\title{
Studi Korelasi antara Kualitas, Profesionalisme dan Komitmen dengan Kinerja Guru SMAN 28 Kab. Tangerang
}

\author{
${ }^{1}$ Agus Iwan Mulyanto \\ Universitas Islam Syekh Yusuf, Tangerang \\ Email: agusiwanmulyanto@unis.ac.id
}

\begin{abstract}
Abstrak
Penelitian ini bertujuan untuk mengetahui apakah terdapat hubungan antara variabel tersebut baik secara terpisah maupun bersama-sama. Penelitian ini digolongkan dalam penelitian korelasional yang terdiri atas tiga variabel bebas kualitas guru $\left(\mathrm{X}_{1}\right)$ dan profesionalisme $\left(\mathrm{X}_{2}\right)$, komitmen $\left(\mathrm{X}_{3}\right)$ dan satu variabel kinerja tenaga pendidik $(\mathrm{Y})$. Populasi penelitian ini adalah seluruh guru yang berstatus tenaga pendidik yang mengajar di SMAN $28 \mathrm{Kab}$. Tangerang, yang berjumlah 71 tenaga pengajar dan sampel diambil sebanyak 40 dengan menggunakan rumus dari Taro Yamane untuk pemilihan sampel. Metode yang digunakan dalam penelitian ini adalah metode survey dengan pendekatan korelasional, dimana data variabel kualitas guru, profesionalitas dan komitmen semuanya dikumpulkan dengan instrumen kuesioner menggunakan skala rating. Semua instrumen diujicobakan dengan uji regresi linear berganda. Hasil penelitian menunjukan bahwa terdapat hubungan positif yang sangat signifikan $(\mathrm{P}<0,05)$ antara kualitas kerja guru, komitmen, dan profisionalisme dengan kinerja tenaga pendidikan dengan persamaan regresi $\mathrm{Y}=0,394+0,384 \mathrm{X}_{1}+0,337 \mathrm{X}_{2}$ $+0,148 \mathrm{X}_{3}$. Berdasarkan hasil penelitian dapat disimpulkan, bahwa kinerja tenaga pendidik dapat ditingkatkan melalui kualitas, profesionalitas dan komitmen.
\end{abstract}

Kata Kunci: studi korelasi, kualitas, profesionalitas, komitmen, dan kinerja tenaga pendidik.

\begin{abstract}
This study aims to determine whether there is a relationship between these variables both separately and together. This research is classified in correlational research which consists of three independent variables teacher quality (X1), professionalism (X2), and commitment (X3) and one teacher performance variable (Y). The population of this research is all teachers who have the status of Educators who teach at SMAN 28 Kab. Tangerang, which amounted to 71 teaching staff and 40 samples were taken using the formula from Taro Yamane for sample selection. The method used in this study is a survey method with a correlational approach, where the variable quality data of teachers, professionalism and commitment are all collected by the questionnaire instrument using a rating scale. All instruments were tested with multiple linear regression tests. The results showed that: there was a very significant positive relationship $(P<0.05)$ between the quality of teacher work, commitment, and professionalism with the performance of education personnel with a regression equation $Y=0.394+0.384 X_{1}+0.337 X_{2}+0.148 X_{3}$. Based on the results of the study it can be concluded, that the performance of educators can be improved through quality, professionalism and commitment.
\end{abstract}

Keywords: correlation studies, quality, professionalism, commitment, and performance teachers. 


\section{A. Pendahuluan}

Kabupaten Tangerang merupakan salah satu kabupaten di provinsi Banten yang dewasa ini sedang giat-giatnya membangun, terlebih kabupaten Tangerang merupakan penyangga Ibu kota Negara Kesaruan Republik Iindonesia yaitu DKI Jakarta. Salah satu sektor penting dalam pembangunan adalah sektor pendidikan sebagaimana dalam visi kabupaten Tangerang yaitu terwujudnya Masyarakat Kabupaten Tangerang yang bertaqwa, berdaya dan berbudaya menuju sejahtera dan salah satu misi diterjemahkan dalam pencanangan untuk mewujudkan dan meningkatkan pemerataan dan kualitas tenaga pendidik dalampenyelenggaraan pendidikan. Sedangkan arah kebijakan dibidang pendidikan Kabupaten Tangerang, difokuskan pada peningkatan dan perluasan kesempatan untuk memperoleh pendidikan dasar dan menengah yakni peningkatan mutu, dan pengembangan sumber daya manusianya dalam hal ini tenaga prndidik melalui pendidikan yang dilakukan sekolah-sekolah yang ada di wilayah kabupaten Tangerang khususnya SMAN 28 Kab. Tangerang, yang pada gilirannya akan berdampak pada Indeks Pembangunan manusia di Kabupaten Tangerang. pemerataan dan perluasan pendidikan merupakan prioritas pembangunan pendidikan di Kabupaten Tangerang. Peningkatan kualifikasi pendidikan dan mutu tenaga pendidik dilakukan dengan mengupayakan peningkatan program pendidikan dan pelatihan guru secara berkesinambungan. Tenaga pendidik merupakan bidang pekerjaan yang menuntut pengabdian tertentu dan memerlukan persyaratan dasar, keterampilan teknis dan sikap kepribadian tertentu serta ditandai oleh adanya tingkah laku yang mencirikan tugas seorang tenaga pendidik sebagai tugas 'profesional'. Keberhasilan pendidikan bukan hanya terletak pada kurikulum yang berlaku namun juga bertolak dari profesionalisme guru dalam melaksanakan tugas pendidikan. Tenaga pendidik yang profesional memerlukan teknik dan prosedur ilmiah, memiliki dedikasi serta menyikapi pekerjaannya pada pelayanan yang bertumpu pada landasan intelektual yang secara sengaja harus dipelajari dan kemudian secara langsung dapat diabadikan bagi kemaslahatan orang lain terutama siswanya. Tenaga pendidik yang profesional dan produktif dibangun melalui penguasaan sejumlah kompetensi yang secara nyata diperlukan untuk mendukung pelaksanaan tugas pekerjaannya. Perlunya mengembangkan kompetensi guru sebagai tenaga pendidik yang terus menerus sehingga penyelenggaraan pendidikan didukung oleh tenaga pendidik yang profesional dalam melaksanakan tugas, mampu menempatkan diri sesuai dengan jabatan, dan memiliki kepribadian yang mendukung pelaksanaan tugasnya sehingga menghasilkan guru yang mempunyai kinerja yang tinggi. Kinerja pada dasarnya dapat dilihat dari dua dimensi, yaitu dimensi individu dan dimensi organisasi. 
Dimensi individu tidak lain melihat kinerja terutama dalam hubungannya dengan karakteristik-karakteristik kepribadian individu yang memiliki sikap mental bahwa mutu kehidupan hari ini harus lebih baik dari hari kemarin, dan hari esok harus lebih baik dari hari ini. Ditinjau dari dimensi keorganisasian, konsep kinerja secara keseluruhan merupakan dimensi lain dari pada upaya mencapai kualitas dan kuantitas suatu proses kegiatan berkenaan dengan bahasan ilmu ekonomi, yang berorientasi kepada bagaimana berpikir dan bertindak untuk mendayagunakan sumber masukan agar mendapat keluaran yang optimum.

Kinerja kerja guru selaku tenaga pendidik intinya adalah hasil kerja atau unjuk kerja yang dilaksanakan oleh setiap guru sebagai pendidik setelah melakukan fungsi dan tugasnya. Fakta di atas telah membuktikan ketidakprofesionalan guru di lapangan dalam mendidik dan mengajar peserta didik. Merujuk pada sumber data tabel 1. bahwa kinerja kerja guru di KabupatenTangerang, masih relatif rendah, diantaranya: 1) pencapaian kualitas kerja $50 \%, 2)$ pencapaian target kerja $60 \%, 3$ ) kesesuaian hasil kerja 50\%, 4) kesesuaian perencanaan waktu yang digunakan $60 \%$, dan 5) kreatifitas dan inovasi guru dalam memberikan pembelajaran 50\%.

Rendahnya kinerja kerja guru tersebut perlu mendapat perhatian yang serius dari pemerintah daerah maupun pusat secara bersama-sama untuk meningkatkan kinerja kerja guru karena hal ini berdampak kepada rendahnya kualitas pendidikan, dan yang perlu mendapat perhatian yaitu faktor kinerja kerja guru yang masih relatif rendah, faktor tersebut perlu dijadikan objek pengkajian mengingat kontribusi yang sangat besar dalam peningkatan kinerja kerja guru dan kualitas pendidikan. Hal inilah yang menjadikan penulis tergerak untuk melakukan penelitian terkait dengan kinerja kerja guru yang dihubungkan dengan variabel iklim organisasi dan motivasi berpretasi guru.

\section{B. Metode}

\section{Rancangan Penelitian}

Rancangan penelitian yang digunakan dalam penelitian ini adalah explanatory research yaitu penelitian yang bertujuan untuk menguji suatu teori atau hipotesis guna memperkuat atau bahkan menolak teori.

\section{Jenis dan Sumber Data}

Dalam penelitian ini adalah data primer yang diperoleh dari wawancara dan penyebaran kuisioner. Data sekunder dalam penelitian ini diperoleh secara tidak langsung melalui buku bacaan yang terkait dengan variabel yang diteliti, data yang diperoleh dari internet, dan jurnaljurnal yang ada.

\section{Populasi dan Sampel}

Populasi yang ada dalam sekolah tersebut adalah sebesar 71 orang dan diambil 40 responden sebagai sampel dengan metode 
pengambilan sampel yaitu simple random sampling atau tehnik pengambilan sampel secara acak sederhana. Tehnik mendapatkan responden adalah dengan cara lotre atau mengundi nama-nama peserta di sekolah tersebut, yang kemudian diambil sebanyak sampel yang dipakai yaitu 40 nama tenaga pendidik.

\section{Metode Analisis Data}

Alat analisis yang digunakan untuk menyelesaikan permasalahan yang ada adalah regresi linier berganda.

\section{Hasil dan Pembahasan}

\section{Analisis Regresi Linier Berganda}

Analisis regresi linier berganda berkaitan dengan studi ketergantungan suatu variabel dependen pada satu atau lebih variabel independen dengan tujuan untuk mengetahui seberapa besar pengaruh variabel independen terhadap variabel dependen. Hasil analisis regresi linear berganda antara variabel independen yaitu kualitas guru, profesionalisme kerja, dan komitmen, serta variabel dependen yaitu kinerja disajikan pada Tabel 1 berikut:

Tabel 1. Hasil estimasi Regresi

\begin{tabular}{ccccc}
\hline Variabel & Koefisien & t-hitung & Sig & Ket \\
\hline (Constant) & 0,394 & & & \\
\hline Kualitas guru (X1) & 0,384 & 8,6035 & 0,001 & Sig \\
\hline Komitmen (X2) & 0,337 & 6,816 & 0,001 & Sig \\
\hline Profesionalisme (X3) & 0,148 & 2,808 & 0,008 & Sig \\
\hline
\end{tabular}

R Square $=0,884$ Signifikansi $=5 \%$

Sumber: data primer, 2015.

Berdasarkan koefisien regresi, maka akan menurunkan kinerja tenaga pendidik persamaan regresi yang dapat dibentuk SMAN 28 Kab. Tangerang. adalah:

$$
\begin{gathered}
\mathrm{Y}=0,394+0,384 \mathrm{X}_{1}+0,337 \mathrm{X}_{2}+ \\
0,148 \mathrm{X}_{3}
\end{gathered}
$$

a. Koefisien regresi dari konstanta diperoleh nilai sebesar 0,394 dengan tanda positif, angka ini memberikan arti bahwa tanpa adanya kualitas sumber daya manusia, profesionalisme kerja, dan komitmen maka 
b. Koefisien regresi dari kualitas guru memiliki pengaruh signifikan terhadap kinerja dengan arah yang positif sebesar 0,384. Hal ini berarti bahwa, jika kualitas sumber daya manusia semakin baik maka akan diikuti dengan meningkatnya kinerja tenaga pendidik SMAN 28 Kab. Tangerang

c. Koefisien regresi dari komitmen kerja memiliki pengaruh signifikan terhadap kinerja dengan arah yang positif sebesar 0,337. Hal ini berarti bahwa, jika profesionalisme kerja semakin baik maka akan diikuti dengan meningkatnya kinerja tenaga pendidik SMAN 28 Kab. Tangerang.

d. Koefisien regresi dari profesionalisme kerja memiliki pengaruh signifikan terhadap kinerja dengan arah yang positif sebesar 0,148. Hal ini berarti bahwa, jika komitmen semakin baik maka akan diikuti dengan meningkatnya kinerja tenaga pendidik SMAN $28 \mathrm{Kab}$. Tangerang.

\section{Uji t}

Pengujian ini dilakukan untuk mengetahui apakah secara parsial variabel independen berpengaruh signifikan terhadap variabel dependen. Tabel distribusi t dicari pada $\alpha=$ 5\% (uji 2 sisi, 0,05: $2=0,025$ ), dengan derajat kebebasan (df) n-k-1 atau 75-3-1 = 71. Berdasarkan pengujianuji t, diperoleh hasil;

a) Kualitas guru $\left(X_{1}\right)$ memiliki nilai $t_{\text {hitung }}>$ $t_{\text {tabel }}$ yaitu $t$ 2,215 > 8,603 dan signifikasi $0,001<0,05$, maka Ho ditolak dan Ha diterima, berarti secara parsial variabel kualitas guru berpengaruh signifikan terhadap kinerja tenaga pendidik di SMAN 28 Kab. Tangerang

b) Komitmen $\left(X_{2}\right)$ memiliki $t_{\text {hitung }}>t_{\text {tabel }}$ yaitu nilai t 2,215 > 6,816 dan signifikasi 0,001 $<0,05$, maka Ho ditolak dan Ha diterima, berarti secara parsial variabel profesionalitas mekerja berpengaruh signifikan terhadap kinerja tenaga pendidik di SMAN 28 Kab. Tangerang;

c) Profesionalisme $\left(X_{3}\right)$ memiliki thitung $>t_{\text {tabel }}$ yaitu nilai t 2,215> 2,808 dan signifikasi $0,008<0,05$, maka Ho ditolak dan $\mathrm{Ha}$ diterima secara parsial variabel komitmen berpengaruh signifikan terhadap kinerja tenaga pendidik di SMAN 28 Kab. Tangerang.

\section{Uji F}

Uji F dimaksudkan untuk mengetahui pengaruh kualitas guru, profesionalisme kerja, dan komitmen terhadap kinerja Tenaga Pendidik secara simultan. Tabel distribusi $\mathrm{F}$ dicari pada $\alpha=5 \%$, dengan derajat kebebasan (df) df1 atau 4-1 = 3, dan df2 n-k-1 atau 40-3$1=36$. Hasil pengujian menunjukkan bahwa $F_{\text {hitung }}>F_{\text {tabel }}(83,643>1,427)$ dan signifikasi $(0,001<0,05)$, maka Ho ditolak dan Ha diterima, artinya kualitas guru, profesionalisme kerja, dan komitmen secara simultan berpengaruh signifikan terhadap kinerja SMAN $28 \mathrm{Kab}$. Tangerang. 


\section{Pembahasan}

\section{Pengaruh Kualitas Tenaga Pendidik terhadap Kinerja Tenaga Pendidik.}

Hasil pengujian koefisien dari analisis regresi linear berganda, menunjukkan kualitas guru, profesionalisme kerja, dan komitmen berpengaruh secara parsial dan simultan terhadap kinerja tenaga pendidik SMAN 28 Kab. Tangerang. Hasil pengujian koefisien dari analisis regresi linear berganda, menunjukkan bahwa kualitas guru, profesionalisme kerja, dan komitmen berpengaruh signifikan terhadap kinerja tenaga pendidik SMAN 28 Kab. Tangerang. dengan arah positif. Penelitian yang dilakukan, menunjukkan bahwa nilai koefisien variabel kualitas guru sebesar 0,384 atau $37,4 \%$ dengan arah positif. Dapat dijelaskan bahwa sumber daya manusia dapat dikatakan berkualitas manakala mereka mempunyai kemampuan untuk melaksanakan kewenangan dan tanggung jawab yang diberikan kepadanya. Kemampuan tersebut hanya dapat dicapai ketika mereka mempunyai bekal pendidikan, latihan dan pengalaman yang cukup memadai untuk melaksanakan tugas dan tanggung jawab yang diberikan (Widodo dalam Kharis 2010:8). Penelitian ini mendukung penelitian Kasanudin (2011) dan Sitohang (2009), bahwa kualitas guru berpengaruh terhadap kinerja SMAN 28 Kab. Tangerang. Sedangkan penelitian ini memberikan hasil yang berbeda dengan penelitian Sibagariang (2008) yang menyatakan kualitas guru tidak memiliki pengaruh terhadap kinerja tenaga pendidik, dikarenakan penempatan tenaga pendidik pada obyek penelitian Sibagarian tidak sesuai dengan latar belakang pendidikannya, sehingga menyebabkan pekerjaan yang ditanganinya tidak sesuai dengan yang diharapkan dan pada akhirnya akan mempengaruhi kinerja pada perusahaan. Kualitas sumber daya manusia dapat dilihat dengan adanya tenaga pendidik yang bekerja sebaik mungkin untuk membawa organisasi menjadi lebih baik. Tenaga pendidik juga memiliki sikap dan perilaku baik terhadap organisasi sehingga etika dalam sekolah maupun terhadap pengguna jasa pendidikan terjaga dengan baik SMAN 28 Kab. Tangerang memiliki hubungan baik dengan tenaga pendidik lainnya. Hubungan baik yang ada diharuskan tetap terjaga oleh setiap tenaga pendidiknya baik terhadap rekan kerja maupun terhadap pengguna jasa. Komitmen tenaga pendidik juga dituntut lebih fleksibel didalam berkomunikasi, baik komunikasi formal maupun informal atau secara langsung maupun tidak langsung. Dengan adanya hubungan baik yang ditunjang dengan komunikasi yang fleksibel maka kegiatan kerjadi dalam lingkungan SMAN 28 Kab. Tangerang dapat dilaksanakan dengan baik, seperti merencanakan kerja yang berhubungan dengan anggaran dan operasi di bidang pelayanan.

Komitmen dalam berkomunikasi antar tenaga pendidik dapat dibangun dengan saling menghargai pendapat baik saat diskusi, 
rapat ataupun dalam kegiatan yang bersifat informal. Komunikasi merupakan hal penting iklim kerja guna menghasilkan kualitas kerja sehingga dengan komunikasi kualitas sumber daya manusia khususnya tenaga pendidik akan lebih jelas nampak dan dapat ditransfer informasi kepada tenaga pendidik lain, sehingga kualitas guru meningkat.

\section{Pengaruh Profesionalisme Kerja terhadap} Kinerja Tenaga Pendidik

Penelitian yang dilakukan, menunjukkan bahwa nilai koefisien variabel profesionalisme kerja sebesar 0,268 atau $26,8 \%$ dengan arah positif. Siagian (2009:163) menyatakan profesionalisme adalah keandalan dan keahlian dalam pelaksanaan tugas sehingga terlaksana dengan mutu tinggi, waktu yang tepat, cermat, dan dengan prosedur yanng mudah dipahami dan diikuti oleh pelanggan. Hasil penelitian ini sejalan dengan yang diungkapkan oleh Cahyani (2007) adanya sikap yang profesionalisme, menjadikan diri seorang untuk bersikap dan berperilaku dengan baik dan akan meningkatkan kinerja yang dihasilkannya, sehingga profesionalisme kerja memiliki pengaruh terhadap kinerja pada tenaga pendidik di dalam SMAN 28 Kab. Tangerang. juga harus ulet, berintegritas dan konsekuen didalam pekerjaan atau profesinya. Tenaga pendidik berusaha selalu menyelesaikan tugas dengan hasil maksimal sehingga tercapai kinerja yang baik dengan standart mutu yang ditetapkan dalam pendidikan. Tenaga pendidik juga bekerja dengan tingkat kelitian yang tinggisehingga bisa meminimalkan kesalahan. Sikap profesionalisme juga ditunjukkan dengan tidak mudahputus asa serta selalu patuh pada prosedur yang sudah ditetapkan perusahaan.

\section{Pengaruh Komitmen Guru terhadap Kinerja Tenaga Pendidik.}

Berdasarkan hasil pengujian tersebut, maka dapat disimpulkan bahwa hipotesis yang menyatakan, "ada pengaruh kualitas guru, profesionalisme kerja, dan komitmen terhadap kinerja tenaga pendidik SMAN 28 Kab. Tangerang" diterima. Hal ini mengindikasikan bahwa jika kualitas guru, profesionalisme kerja, dan komitmen, memiliki nilai positif, maka akan memberikan pengaruh dalam meningkatkan kinerja tenaga pendidik SMAN 28 Kab. Tangerang.

\section{Kesimpulan dan Saran}

\section{Kesimpulan}

Berdasarkan hasil analisis yang telah dilakukan pada penelitian ini, maka dapat ditarik kesimpulan sebagai berikut:

Kualitas guru berpengaruh positif dan signifikan terhadap kinerja tenaga pendidik SMAN 28 Kab. Tangerang. Hal ini membuktikan bahwa kualitas tenaga guru yang baik, memiliki prilaku baik, dapat berkomunikasi secara fleksibel, dan dapat berhubungan baik antara tenaga pendidik satu dengan lainnya maka akan memberikan 
pengaruh dalam meningkatkan kinerja tenaga pendidik SMAN $28 \mathrm{Kab}$. Tangerang.

Profesionalisme kerja berpengaruh positif dan signifikan terhadap kinerja tenaga pendidik SMAN 28 Kab. Tangerang. Hal ini membuktikan bahwa adanya profesionalisme kerja yang berprinsip pada efektif dan efisien, berintegritas dan konsekuen maka akan memberikan pengaruh dalam meningkatkan kinerja tenaga pendidik SMAN 28 Kab. Tangerang.

Komitmen berpengaruh positif dan signifikan terhadap kinerja tenaga pendidik. Hal ini membuktikan bahwa adanya komitmen tenaga pendidik didalam berkerjaakan memberikan pengaruh dalam meningkatkan kinerja tenaga pendidik SMAN $28 \mathrm{Kab}$. Tangerang.

Kualitas guru, profesionalisme kerja, dan komitmen secara simultan berpengaruh positif dan signifikan terhadap kinerja tenaga pendidik SMAN $28 \mathrm{Kab}$. Tangerang.

\section{Keterbatasan Penelitian}

Penelitian ini masih memiliki keterbatasan serta kekurangan yaitu sebagai berikut:

Penelitian ini hanya menggunakan 3 variabel independen untuk mengukur kinerja Tenaga Pendidik di SMAN 28 Kab. Tangerang, sedangkan masih ada beberapa variabel lain yaitu seperti motivasi, lingkungan kerja yang bisa digunakan untuk mengukur kinerja Tenaga Pendidik di SMAN 28 Kab. Tangerang. Jadi di dalam penelitian ini masih membutuhkan informasi tambahan terkait tentang variabel lain yang digunakan untuk dapat mengukur kinerja tenaga pendidik SMAN 28 Kab. Tangerang. Penelitian ini hanya dilakukan pada SMAN 28 Kab. Tangerang saja, sehingga hasil penelitian ini tidak dapat diterapkan di sekolah-sekolah lain.

\section{Referensi}

Cahyani, Nur. 2007. "Analisis Pengaruh Profesionalisme Pemeriksaan Pajak, Kepuasan Kerja dan Komitmen Organisasi terhadap Kinerja Tenaga Pendidik”. Tesis. Semarang: Universitas Diponegoro Semarang http://eprints.undip.ac.id/18439/1/Nur_Cahyani.pdf .

Fadliyansya, Fajar. 2013. "Pengaruh Kecerdasan Emosional terhadap Komitmen dan Kinerja Tenaga Pendidik pada Rumah Sakit Islam”. Skripsi. Tidak dipublikasikan. Lumajang. Universitas Jember. 
Kasannudin, Mukhamad. 2011. "Pengaruh Kualitas SDM Pengelola Koperasi terhadap Kinerja Koperasi Pondok Pesantren di Kabupaten Demak”. Skripsi. Semarang: Institute Agama Islam Negeri Walisongo Semarang. http://library.walisongo.ac.id/digilib/files/disk1/132/ jtptiain-gdlmukhamadka-6600-1-pengaruh-p.pdf.

Kharis, Abdul. 2010. "Pengaruh Kualitas SDM terhadap Pelaksanaan Sistem Pengendalian Intern Pada PT. Avia Avian". Skripsi. Universitas Pembangunan Nasional "VETERAN". http://www.google.com/url?sa=tHYPERLINK $h t t p: / / w w w . g o o g l e . c o m / u r l ? s a=t \& r c t=j \& q=\& e s r c=s \& \operatorname{source}=w e b \& c d=2 \& v e d=0 C B O$ QFjAB\&url= http://core.ac.uk:8081/download/pdf/12215856.pdf\&ei=n3ICVfmsNs6XuATn7IH4CQ\&u $s g=A F Q j C N G W L N q K u d s F b 3 H R v j R W_{-}$VfE38 Ed9Q\&sig2=ILihy3CLRnN4YJw-

ZIwrtw".

Mangkunegara, A.P. 2006. Manajemen Sumber Daya Manusia Perusahaan. Bandung: Rosda.

Robbins, Stephen P. 2006. Perilaku Organisasi. Jakarta: PT Indeks Kelompok Gramedia.

Siagian, Sondang P. 2009. Adminitrasi Pembangunan. Jakarta: Bumi Aksara.

Sibagariang, Arisonaldi. 2013. "Pengaruh Kualitas SDM, Komunikasi, Sarana Pendukung dan Komitmen Organisasi terhadap Kinerja SKPD (Studi Empiris pada Pemerintah Kota Sibolga)".

Skripsi. Padang: Universitas Negeri Padang. http://www.google.com/url sa=tHYPERLINK

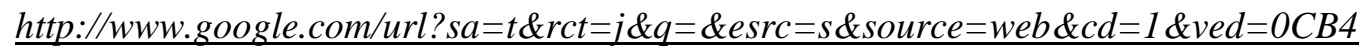
QFjAA\&url=. http://ejournal.unp.ac.id/students/index.php/akt/article/download/61/49\&ei=_XUCVeDA AZOTuASqnoHwCQ\&usg=AFQjCNGIwklJoIKAAQBqQEBNVEXnU_Q\&sig2=8YdykQ nVYTBuYQS3wuLvOw\&bvm=bv.88198703,d.c2 E".

Sitohang, Sonang. 2009. "Pengaruh Kualitas Sumber Daya Manusia Terhadap Kinerja Pengrajin Sentra Industri Kecil Tenun Ikat”. Jurnal: STIE Surabaya. http://www.google.com/url?sa=tHYPERLINK http://www.google.com/url $? s a=t \& r c t=j \& q=\&$ esrc $=s \&$ source $=$ web $\& c d=1 \& v e d=0 C B s Q$ FjAA\&url=http://www.stiesia.ac.id/jurnal/index.php/article/download_selection_article/ 2/20130731004/1\&ei=FHcCVbK-Ec6IuwTm4HIBQ\&usg= FQjCNGoXo6Ph7E2qmYOhn95eA7LT3lug\&sig2=a-FzKvNgpTiI_WXyPTbFWQ\&bvm= bv.88198703,d.c2E". 